\begin{tabular}{|cl}
\hline Jurnal Teknologi Kimia Unimal & $\begin{array}{l}\text { Jurnal } \\
\text { Teknologi } \\
\text { Kimia } \\
\text { Uttp://ojs.unimal.ac.id/index.php/jtk }\end{array}$ \\
\hline
\end{tabular}

\title{
EKSTRAKSI RESIN DARI BUAH JERNANG (Dragon Blood) METODE UNDER KRITIS PELARUT UNTUK PENINGKATAN KUALITAS MUTU RESIN JERNANG SESUAI SNI 1671:2010
}

\author{
${ }^{1}$ Saifuddin, ${ }^{2}$ Nahar, ${ }^{3}$ Indra Mawardi \\ 1,2 Jurusan Teknik Kimia Politeknik Negeri Lhokseumawe(PNL) \\ ${ }^{3}$ Jurusan Teknik Mesin Politeknik Negeri Lhokseumawe \\ Jln.Medan-Banda Aceh, Km 280,3. Buket rata Lhokseumawe \\ e-mail: odinx66@yahoo.com
}

\begin{abstract}
ABSTRAK
Resin jernang (dragon blood) merupakan getah termahal di dunia. Resin tersebut diperoleh dari buah jernang yang tumbuh hanya di pulau Sumatra dan kalimatan. Resin jernang sangat diminati oleh Negara Cina, Hongkong, dan Singapura, karena mengandung senyawa dracohordin yang berpotensi sebagai bahan obat secara biologis dan aktivitas farmakologis seperti antimikroba, antivirus, antitumor, dan aktivitas sitotoksik. Proses ekstraksi resin jernang dari buah jernang secara konvensional secara basah dengan metode maserasi merupakan salah satu cara pengolahan buah jernang yang dilakukan oleh masyarakat pengolah jernang di Kabupaten Bireuen Provinsi Nangroe Aceh Darussalam, Namun masih ada kendala yang cukup signifikan yaitu.mutu rendemen yang diperoleh lebih rendah dibandingkan dengan rendemen resin jernang .dari.teknologi Inovasi yang dilakukan oleh Bambang, dengan proses ekstraksi maserasi menggunakan pelarut metanol menghasilkan rendemen yang lebih tinggi dari pada proses ekstraksi metode maserasi yang dilakukan oleh kelompok pengolah jernang di Kabupaten Bireuen, akan tetapi penggunaan metanol sebagai pelarut akan menaikkan biaya produksi karena harganya relatif lebih mahal dan tidak ramah lingkungan. Penelitian ini melakukan proses ekstraksi dua tahap yaitu metode maserasi dan metode under kritis pelarut dengam menggunakan pelarut air, karena harganya murah, jumlah melimpah dan ramah lingkungan. Hasil penelitian diperoleh mutu resin jernang yang lebih baik dari resin jernang yang diperoleh kelompok pengolah jernang di kabupaten Bireuen. Dengan metode maserasi didapatkan kelas mutu resin jernang kelas $A$ berdasarkan spesifikasi persyaratan mutu jernang (SNI 1671:2010) dengan kadar.resin(b/b) 73\%, Kadar air(b/b) 6,8\%, Kadar abu(b/b) 7\%, kadar pengotor(b/b) $32 \%$, titik leleh $88^{\circ} \mathrm{C}$ dan bewarna merah. Sedangkan perlakuan dua tahap diperoleh kelas mutu antara kelas $A$ dan Mutu super dengan.kadar.resin(b/b).86\%, Kadar air(b/b) 6,5\%, Kadar abu(b/b) 2,8\%, kadar pengotor(b/b) 9\%, titik leleh $88^{\circ} \mathrm{C}$ dan bewarna merah tua.
\end{abstract}


Kata kunci: ekstraksi, under kritis, jernang, SNI

\title{
The extraction of dragons blood resin by using under critical solvent method to improve its quality accordance to SNI 1671:2010
}

\begin{abstract}
Resin jernang (dragon blood) is the world's most expensive sap. The resin obtained from jernang fruit that grows only on the islands of Sumatra and Borneo. Jernang resin is in demand by the State of China, Hongkong and Singapore, because they contain compounds that have the potential dracohordin as a medicinal ingredient in the biological and pharmacological activity such as antimicrobial, antiviral, antitumor and cytotoxic activity. The process of extracting resin jernang of fruit jernang conventionally be wet with maceration method is one way of processing fruits jernang done by people processing jernang in Bireuen Nanggroe Aceh Darussalam, however there are still obstacles significant, namely the quality of the yield obtained is lower than to yield resin jernang of technological innovation carried out by a full-blooded with the extraction process maceration using methanol produce a yield that is higher than the extraction process maceration method carried out by the processor jernang in Bireuen, but the use of methanol as a solvent would raise production costs due the price is relatively more expensive and not environmentally friendly. This research process is a two-stage extraction maceration method and the method using a solvent with method under criticali solvent. because the price is cheap, abundant and environmentally friendly number. The results were obtained quality resin jernang better than resin obtained jernang. jernang processing group in Bireuen district. Obtained by maceration method jernang resin quality class A class based on the specification of quality requirements jernang (SNI 1671: 2010) with kadar resin (b / b) 73\%, water content (w / w) of 6.8\%, ash content (w / b) $7 \%$, impurity content $(\mathrm{w} / \mathrm{w}) 32 \%$, the melting point of $88^{\circ} \mathrm{C}$ and red colored. While the two-stage treatment obtained quality class between class A and Quality super dengan.kada resin $(\mathrm{b} / \mathrm{b}) .86 \%$, water content $(\mathrm{w} / \mathrm{w})$ of $6.5 \%$, ash content $(\mathrm{w} / \mathrm{w})$ of $2.8 \%$, levels of impurities $\left(\mathrm{w} / \mathrm{w}\right.$ ) of $9 \%$, the melting point of $88^{\circ} \mathrm{C}$ and colored dark red.
\end{abstract}

Keywords: Extraction, Undercritical, Dragon Blood, and SNI

\section{Pendahuluan}

Resin jernang (dragon blood) merupakan getah termahal di dunia dan sangat dicari oleh dunia farmasi. ini dikarenakan dalam getah jernang (resin) terdapat kandungan senyawa Dracohordin yang sangat dibutuhkan oleh dunia farmasi. Dracorhodin merupakan konstituen utama yang ditemukan dalam buah jernang (Dragon Blood). Dracorhodin termasuk Senyawa antosianin alami dan digunakan sebagai zat farmasi ampuh karena aktivitas biologis dan farmakologisnya seperti antimikroba, antivirus, antitumor, dan aktivitas sitotoksik.. (Gupta et all, 2008).

Resin jernang merupakan resin hasil sekresi buah rotan jernang. Resin tersebut menempel dan menutupi bagian luar buah rotan, dimana untuk 
mendapatkannya diperlukan proses ekstraksi buah. Jernang secara tradisional dimanfaatkan sebagai bahan obat. Di samping itu, jernang dimanfaatkan sebagai bahan pewarna untuk mengecat barang-barang pernis, dahulu dan sekarang.

Komponen kimia utama pada resin jernang adalah resin ester dan dracoresino tannol (57- 82\%). Selain itu, resin berwarna merah dan juga mengandung senyawa-senyawa seperti dracoresene (14\%), dracoalban (hingga 2,5\%), resin tak larut $(0,3 \%)$, residu $(18,4 \%)$, asam benzoat, asam benzoilasetat, dracohodin dan beberapa pigmen terutama nordracorhodin dan nordracorubin ( Chu, 2006 dalam Risna, 2006).

Penelitian ini terkait efisiensi proses ekstraksi dalam mengekstrak resin turunan antosianin dari bahan baku buah jernang. Penggunaan metode gabungan maeserasi dan infundasi dengan alasan rekayasa air sebagai pelarut tidak menimbulkan efek negative bagi kesehatan, limbah yang dihasilkan ramah lingkungan, proses ekstraksi cepat dan murah. Sehingga dapat menekan biaya produksi . Pada umumnya pelarut paling baik digunakan adalah methanol, akan tetapi mengingat harga dan efek yang yang ditimbulkan oleh limbah methanol maka ekstrasi metode teknik infundasi merupakan yang paling cocok untuk diaplikasikan sebagai tekhnologi tepat guna untuk kelompok pengolah jernang, Penggunaan pelarut dalam pengolahan secara tradisonal oleh kelompok pengolah jernang di kabupaten Bireuen, dalam mengekstraksi resin jernang harus memakai pelarut air dengan jumlah yang besar dibandingkan dengan berat jernang agar resin dapat terekstraksi dengan sempurna, hal ini sangat tidak efiseien.

Dalam hasil penelitian ini yang dianalisa adalah kadar resin, kadar air, kadar abu dan titik leleh pada resin yang diperoleh setelah ekstraksi. Dan selanjutnya disesuaikan dengan SNI.

\section{Bahan dan Metode}

\subsection{Bahan penelitian}

Bahan yang digunakan adalah buah jernang, dan aquadest sebagai pelarut resin untuk di ekstraksi dalam beaker glass $1000 \mathrm{ml}$, Untuk proses ekstraksi dilakukan dengan dua metode yaitu metode pertama dengan proses maeserasi dan 
metode kedua simultan maserasi di bawah subkritis air dalam autoclave pada temperature $90^{\circ} \mathrm{C}$ dan tekanan atmosfer.

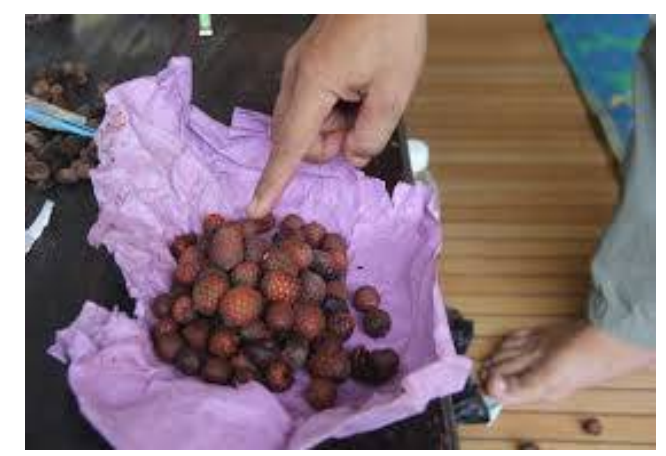

Gambar 1. Buah jernang

\subsection{Ekstraksi (maserasi) menggunakan pelarut Air.}

Ekstraksi jernang metode maserasi merupakan salah satu ekstraksi cara basah dengan mengunakan pelarut untuk mendapatkan filtrat yang mengandung resin jernang, pengunaan pelarut methanol dalam ekstraksi jernang dengan metode maserasi menghasilkan rendemen sebesar 73,01\% selama 24 jam dibandingkan dengan mengunakan pelarut air (Bambang.2010)

Ekstrasi basah dengan menggunakan pelarut air penellitian ini dilakukan dengan memasukkan buah jernang yang sudah ditumbuk ke dalam wadah yang berisi pelarut dengan perbandingan 1:1, 1:2, 1;3. larutan tersebut diaduk-aduk sampai cairan tersebut berwarna merah pekat dengan waktu ekstraksi selama 72 jam. Selanjutnya cairan tersebut disaring dengan saringan kasar untuk memisahakan buah jernang dengan buah kasar. Selanjutnya di saring dengan kertas saring . hasilnya dikeringkan dan dianalisa.

\subsection{Ekstraksi under kritis pelarut menggunakan Air.}

Hasil ekstraksi dari metode maeserasi sebelum disaring dilakukan pemanasan dalam autoclave suhu $90^{\circ} \mathrm{C}$ selama 30 menit, hasil ekstraksi berupa gumpalan dipisakan dari cairan dan dikeringkan untuk kemudian dianalisa.

\subsection{Penentuan rendemen resin jernang}

Dalam penentuan kadar resin,contoh yang diuji harus cukup kering dan biasanya digunakan contoh dari bekas penentuan kadar air. Jika contoh masih basah maka selain memperlambat proses ekstraksi,air dapat turun kedalam labu suling sehingga akan mempersulit penentuan berat tetap dari labu suling. 


$$
\text { Rendemen resin }(\%)=\frac{A}{\text { Berat contoh }} \times 100 \%
$$

Tabel 1. Sifat fisika-kimia jernang (SNI 01-1671-1987)

\begin{tabular}{|c|c|c|c|c|c|}
\hline \multirow{2}{*}{ No } & \multirow{2}{*}{$\begin{array}{c}\text { Sifat } \\
\text { (Properteis) }\end{array}$} & \multicolumn{2}{|c|}{ Jernang (Dragon's blood) } & \multicolumn{2}{|c|}{ SNI (Indonesia National Standard) } \\
\cline { 3 - 6 } & SAD & SMJ & $\begin{array}{c}\text { Mutu I } \\
\text { (Quality I) }\end{array}$ & $\begin{array}{c}\text { Mutu II } \\
\text { (Quality II) }\end{array}$ \\
\hline 1 & $\begin{array}{c}\text { Kadar air (\%) } \\
\text { (Moisture content) }\end{array}$ & 4,4 & 3,2 & $\begin{array}{c}\text { Maks.3 } \\
\text { (max) }\end{array}$ & $\begin{array}{c}\text { Maks.6 } \\
\text { (max) }\end{array}$ \\
\hline 2 & $\begin{array}{c}\text { Kadar Kotoran (\%) } \\
\text { (Impurity) }\end{array}$ & 16,0 & 5,2 & $\begin{array}{c}\text { Maks.14 } \\
\text { (max) }\end{array}$ & $\begin{array}{c}\text { Maks.39 } \\
\text { (max) }\end{array}$ \\
\hline 3 & $\begin{array}{c}\text { Kadar Abu (\%) } \\
\text { (Ask content) }\end{array}$ & 2,8 & 0,7 & $\begin{array}{c}\text { Maks.8 } \\
\text { (max) }\end{array}$ & $\begin{array}{c}\text { Maks.20 } \\
\text { (max) }\end{array}$ \\
\hline 4 & $\begin{array}{c}\text { Titik Leleh }\left({ }^{\circ} \mathrm{C}\right) \\
\text { (M elting point) }\end{array}$ & 105 & 80 & $\begin{array}{c}80-120^{\circ} \mathrm{C} \\
80-120^{\circ} \mathrm{C}\end{array}$ \\
\hline
\end{tabular}

\subsection{Kadar air}

Kadar air adalah perbedaan antara berat bahan sebelum dan sesudah dilakukan pemanasan. Setiap bahan bila diletakkan dalam udara terbuka kadar airnya akan mencapai keseimbangan dengan kelembaban udara disekitarnya. Kadar air ini disebut dengan kadar air seimbang. Setiap kelembaban relatif tertentu dapat menghasilkan kadar air seimbang tertentu pula. Dengan demikian dapat dibuat hubungan antara kadar air seimbang dengan kelembaban relative. Prinsipnya menguapkan air yang ada dalam bahan dengan jalan pemanasan. Kemudian menimbang bahan sampai berat konstan yang berarti semua air sudah diuapkan.

$$
\text { Kadar air }=\frac{A-\bar{E}}{\text { gram contoh }} \times 100 \%
$$

\subsection{Penentuan kadar abu}

Penetapan kadar abu Abu adalah sisa pembakaran sempurna bahan organik (residu yang tidak menguap bila suatu bahan dibakar dengan cara tertentu). Secara kimia abu dapat didefinisikan sebagai oksida logam dan bahanbahan lain yang tidak dapat dibakar., abu merupakan indicator tingkat derajat kebersihan dimana semakin besar tingak abunya maka tingkat pengotornya juga tinggi. Secara alami didalam resin jernang terdapat logam. Logam-logam ini merupakan komponen hara tumbuhan yang merupakan komponen molekul penting dalam reaksi biokimiawi tumbuhan. Logam-logam tersebut merupakan abu fisiologis. Pada saat penyiapan, buah jerenang dapat terkotaminasi oleh tanah, pasir, dan sebagainya. Pasir merupakan senyawa silikat yang tidak terbakar. 
Senyawa silikat ini tidak larut asam, sehingga merupakan komponen penyusun abu tidak larut asam. Oleh karena itu, kadar abu dalam limbah jernang harus ditentukan untuk melihat kadar senyawa pengotor yang terkandung di dalamnya. Bila kadar abu pada limbah jernang melebihi persyaratan yang ditentu maka hasil resinnya tersebut tidak boleh digunakan dimanfaatkan resinnya.

$$
\text { Kadar abu }=\frac{\bar{z}-A}{\text { gram contah }} x 100 \%
$$

\subsection{Penentuan Titik Leleh}

Titik leleh adalah suhu yang teramati ketika zat padat (jernang) mulai meleleh sampai semua partikel berubah menjadi cair, dimana temperatur zat padat (jernang) berubah ujud menjadi zat cair pada tekanan suatu atmosfer. Untuk penentuan titik leleh diperlukan sampel jernang seberat 1 gram dan dimasukknan kedalam suatu tabung kaca kapiler. Tabung yang berisi sampel jernang dipasang pada alat penentu titik leleh. Setelah alat dijalankan, suhu pada saat sampel mengalami perubahan bentuk dari fase padat lunak ke fase cair dicatat sebagai titik leleh jernang.

\section{Hasil dan Diskusi}

\section{a. Metode Maeserasi}

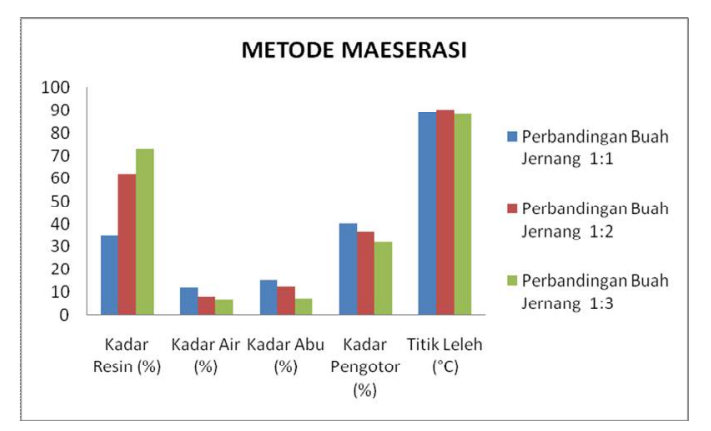

Gambar 2. Pengaruh rasio jernang dan air terhadap kwalitas resin jernang dengan metode maserasi

Dengan metode maserasi didapatkan kelas mutu resin jernang kelas A berdasarkan spesifikasi persyaratan mutu jernang (SNI 1671:2010) dengan kadar.resin(b/b) 73\%, Kadar air(b/b) 6,8\%, Kadar abu(b/b) 7\%, kadar pengotor(b/b) $32 \%$, titik leleh $88^{\circ} \mathrm{C}$ dan bewarna merah. 
Pengamatan jumlah pelarut terhadap jumlah persen rendemen yang di peroleh, semakin banyak pelarut maka semakin banyak jumlah resin yang terekstraksi karna lebih banyak resin yang terbawa dengan pelarut dan keluar dari membran sel. Hal ini disebabkan selama proses pengekstrasian komponen kimia dalam sel tanaman yaitu, pelarut yang telah ditentukan akan menembus dinding sel dan masuk kedalam rongga sel yang mengandung zat aktif (missal antosianin). Zat aktif ini akan larut dalam pelarut karena kesamaan polaritas dan hal ini akan menyebabkan larutannya menjadi pekat (konsentrasi meningkat).

\section{b. Metode maeserasi diikuti metode under kritis air}

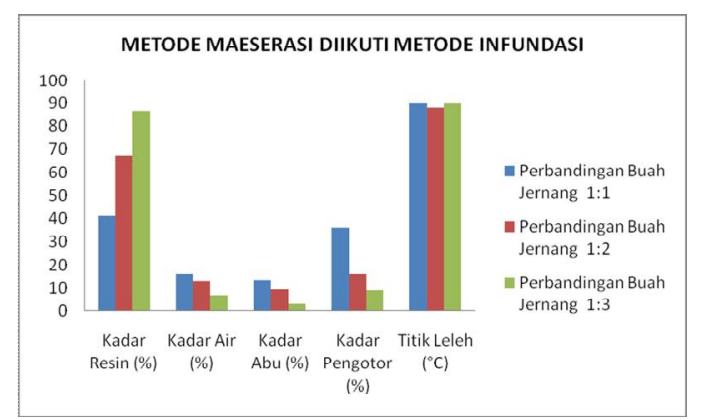

Gambar 3. Pengaruh rasio jernang dan air terhadap kwalitas resin jernang metode maserasi diikuti under kritis air (infundasi)

Perlakuan dua tahap maserasi diikuti infundasi diperoleh kelas mutu antara kelas A dan Mutu super dengan.kadar.resin(b/b).86\%, Kadar air(b/b) 6,5\%, Kadar $\mathrm{abu}(\mathrm{b} / \mathrm{b}) 2,8 \%$, kadar pengotor(b/b) $9 \%$, titik leleh $88^{\circ} \mathrm{C}$ dan bewarna merah tua. pada perbandingan buah jernang dengan aquadest 3:1, dan didapat mutu yang paling bagus

Suhu pada metode under kritis ( infundasi) dipertahankan dibawah titik didih air sehingga terjadi penggumpalan resin bagian atas dan mudah dipisahkan dengan saringan biasa. Peningkatan suhu pemanasan akan berkurang intensitas warna dari larutan ekstrak resin dari buah jernang, hal ini disebabkan karena terdegradasinya antosianin tersebut, degradasi antosianin dapat berupa putusnya ikatan glikosidik yang menyebabkan tidak stabilnya antosianidin serta terjadinya perubahan struktur antsosianidin menjadi senyawa kalkon. 


\section{Simpulan}

Metode maserasi: Semakin banyak pelarut yang digunakan semakin banyak kadar resin yang diperoleh dengan kualitas yang lebih bagus. Metode maserasi diikuti metode under kritis air: peningkatan kadar resin lebih banyak sehingga dari kelas mutu jernang sesuai SNI diperoleh mutu resin jernang lebih baik yaitu antara mutu super dan mutu A. Peningkatan mutu jernang akan menaikan nilai jual resin jernang.

\section{Daftar Pustaka}

Anonim. 2010. Getah jernang. SNI 1671:2010. Badan Standardisasi Nasional. Jakarta.

Bambang W, 2010. Dragon's blood extraction at various seed maturity levels and their physico-chemical properties (RPI-5), Funded under the Rattan Research Grant Program of the ITTO-Philippines-ASEAN Rattan Project (PD 334/05 Rev. 2 (I).

Coppen, J.J.W. 1995. Gum, resins, and latexes of plant origin. Non Wood Forest Products. No.6. FAO,Roma.

Gupta, D.; B. Bleakley and R. K. Gupta. 2008. Dragon's blood : Botany, chemestry and t h e r a p e u t i c u s e s. Jou r n a l o f Ethnopharmacology, 115(3) : 361-380.

Grieve M. 2006. Dragon's Blood [Internet]. [diunduh 2014 Jan 21]. Tersedia pada: http//www.botanical.com/botanical/mgmh/d/dragon20.html.

Rao,G.S.R.; M.A. Gehart; R.T. Lee; L.A. Mitscher and S. Drake. 1982. Antimicrobial agents from higher plants: Dragon's blood resin. Journal of Natural Products 45:646-648.

Risna, R. A. 2006. Dragon's blood tumbuhan obat yang menjanjikan dari Taman Nasional Bukit Tigapuluh. Warta Kebun Raya, Pusat Konservasi 6.No. 1 : 45 - 49 Shi, J.; R. Hu; Y. Lu; C. Sun and T. Wu. 2009.

Rondao RJBL. 2012. Dragon's blood [disertasi]. Coimbra (PT): University of Coimbra.

Rustiami H, Setyowati FM, Kartawinata K. 2004. Taxonomy and uses of Daemonorops draco (Willd.). J Trop Ethnobiol. 1(2):65-75. 
Soemarna Y. 2009. Ekologi dan teknik perkecambahan dan pembibitan rotan jernang pulut (Daemonorops draco (Willd.) Blume). JPHH.6(1):3-39.

Sumadiwangsa, 1973; Sumadiwangsa 2000 dan Coppen 1995 dalam Waluyo, 2008).

Sumarna,y.,2005 China Butuh 400 ton jerenang rotan dari Indonesia.www.kapanlagi.com. Diakses pada tanggal 6 Desember 2014.

Shi, J.; R. Hu; Y. Lu; C. Sun and T. Wu. 2009. Single-step purification of dracorhodin from dragon's blood resin of using high-speed counter-current chromatography combined with pH modulation. J.Sep.Sci. 32:4040-4047.

Purwanto Y, Polosakan Y, Susiarti S, Walujo EB. 2005. Ekstraktivisme jernang (Daemonorops spp.) dan kemungkinan pengembangannya: studi kasus di Jambi, Sumatra, Indonesia. Laporan Teknik Bidang Botani Puslitbang LIPI. Bogor (ID): LIPI.

Toriq, U. 2013. Senyawa Kimia Penciri Jernang untuk Pembaruan Parameter Standar Nasional Indonesia. Fakultas Matematika Dan Ilmu Pengetahuan Alam. Institut Pertanian Bogor. (Skripsi).

Winarni I, Waluyo TK, Hastoeti P. 2005. Sekilas tentang jernang sebagai komoditi yang layak dikembangkan. Di dalam: Penguatan Industri Kehutanan Melalui Peningkatan Efisiensi, Mutu, dan Diversifikasi Produk Hasil Hutan. Prosiding Ekspose Hasil-Hasil Litbang Hasil Hutan. Bogor, 14 Desember 2004. Bogor (ID): Pusat Penelitian dan Pengembangan Hasil Hutan. hlm 173-177. 